\title{
Teenagers and Precision Psychiatry: A Window of Opportunity
}

\author{
Maya Sabatello ${ }^{a, b}$ Ying Chen ${ }^{c}$ Carmen Fiorella Herrera ${ }^{d}$ Erika Brockhoffe \\ Jehannine Austin ${ }^{f}$ Paul S. Appelbaum ${ }^{g}$ \\ aDepartment of Medicine, Columbia University, New York, NY, USA; ${ }^{b}$ Department of Medical Humanities and Ethics, \\ Columbia University, New York, NY, USA; ' New York State Psychiatric Institute, New York, NY, USA; dYale New Haven \\ Health - Bridgeport Hospital, Bridgeport, CT, USA; ${ }^{e}$ Mount Sinai West, New York, NY, USA; ${ }^{f}$ Department of Psychiatry \\ and Medical genetics, University of British Columbia, Vancouver, BC, Canada; ${ }^{9}$ Department of Psychiatry, Columbia \\ University, New York, NY, USA
}

\section{Keywords}

Adolescents · Precision psychiatry · Empowerment ·

Gene-environment interactions

\begin{abstract}
Objective: Precision medicine raises hope for translating genetic-based knowledge about psychiatric risks into mental health benefits by motivating health-related, risk-reducing behaviors. Teenagers (ages 14-17) are an important agegroup to engage in preventive efforts but, their views about psychiatric genetics are understudied. Method: An online survey with a nationally representative sample of teenagers ( $n=417$ ) was conducted. Participants were randomly assigned to receive 1 of 2 handouts, 1 emphasizing the genetic underpinnings of psychiatric conditions; the other agencyoriented and focusing on gene-environment interactions. Survey questions queried their views about behavioral changes in response to psychiatric genetic risk information and expressed willingness to undertake them. Participants' decision-making characteristics (i.e., self-efficacy, empowerment, intolerance of uncertainty, and sensation-seeking) were assessed at baseline. Results: Teenagers strongly valued the information provided and its potential usefulness for
\end{abstract}

their mental health. Information about psychiatric genetics alone impacted views about the causes of mental illness. Contrary to our hypothesis, the type of handout did not impact participants' expressed willingness to make behavioral changes to reduce their risk of developing a psychiatric condition, but their sense of empowerment played a key role in their responses. Conclusion: Educating teenagers about gene-environment interactions may help facilitate the translational efforts of precision psychiatry. Research with teenagers across racial/ethnic groups, especially those with family histories, is needed to better understand the factors that impact teenagers' empowerment in psychiatric genomic settings and to identify measures, including the best enablers of empowerment (e.g., educators, parents), which would allow them to reap the benefits of precision psychiatry.

(c) 2021 S. Karger AG, Basel

\section{Introduction}

Precision medicine holds great promise for adolescent psychiatry ("precision psychiatry") [1]. This approach aims to provide a more customized approach to health care by tailoring preventive, diagnostic, and therapeutic

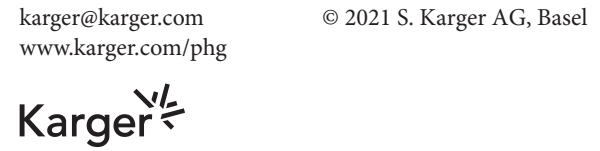


options to individuals' genetic variability, environmental factors, and lifestyle choices. Given that the genetic underpinnings of psychiatric conditions are complex and mostly non-deterministic, existing data are insufficiently predictive to motivate specific preventive or treatment interventions [2]. However, studies of interactions between genetic vulnerability and environmental stressors (e.g., poverty [3]), as well as personal environmental triggers (e.g., substance use and unmanaged stress), demonstrate an impact on psychiatric outcomes $[4,5]$. Thus, ongoing research on gene-environment interactions has led to hope that next-generation sequencing technologies, better defined environmental variables, and studies of large cohorts will yield more robust findings $[2,6]$. These approaches highlight the possibility of - and need for translating genetic-based knowledge about psychiatric risks into mental health benefits by motivating healthrelated, risk-reducing behaviors. While such translational genomic efforts are already underway, there is hope that, in the long-run, they will deliver the promised benefits of precision psychiatry [7-9].

Adolescence is an optimal life stage to embark on such translational genomic efforts in psychiatry. Studies indicate that many adults with recurring psychiatric disorders (e.g., major depression) experienced initial episodes while teenagers [10]. More generally, it is estimated that half of lifetime diagnosable psychiatric conditions begin by age 14 , and three-fourths begin by age 24 [11]. Teenagers' impulsive, risk-taking behavior and influence by peers further increase their risk for psychiatric disorders. Studies indicate, for example, that the majority of teens with substance abuse issues began using drugs due to peer pressure, a behavior that, in interaction with genetic vulnerability, increases the risk for schizophrenia [12]. Insofar as precision psychiatry - the ultimate goal of translational genomic efforts - can encourage risk-reducing behaviors and prevent initial episodes from developing into life-long conditions, it will serve an important end.

Several studies that explored the potential impact of translational genomic efforts are encouraging. They found that many adolescents, especially those with a family history of the relevant condition, report that they would be willing to make behavioral changes if the risk were actionable $[13,14]$. Yet none of these studies focused on psychiatric disorders. Studies of adults further suggest that the likelihood of behavioral changes in response to genetic data depends on various factors, including quality of intervention, an individual's risk assessment, and belief in one's ability to mitigate the risk [15], but there is very little research with teenagers. Similarly, although personal factors, for example, self-efficacy $[16,17]$, empowerment $[18,19]$, sensation-seeking $[20]$, and tolerance of uncertainty [21] have been shown to play a role in the management and treatment of psychiatric conditions, their potential impact on teenagers' willingness to change behaviors in light of information about psychiatric genetic predisposition is unknown.

With the expanded use of next-generation genetic sequencing technologies, ongoing efforts to better define gene-environment interactions that affect mental health outcomes, and studies of ever-larger cohorts, there is hope that more robust findings will emerge in the near future [6]. How this information will impact teenagers is unknown. Some scholars raised concerns that positive genetic results may trigger anxiety and have long-term psychological costs for teenagers and their parents [22]. Others suggested that, as externalizing behaviors and risktaking are often considered hallmarks of adolescence, teenagers who learn that they have lower genetic vulnerability will increase engagement in riskier behaviors, such as alcohol and substance use [23]. Conversely, there is hope that learning about psychiatric genetics, and especially gene-environment interactions $(\mathrm{GxE})$ in psychiatry - arguably a more empowering form of information - may be a key factor in the successful implementation of adolescent precision psychiatry. We report on findings from a survey of a nationally representative sample of adolescents $(n=417)$ that gauged views about psychiatric genetic risk information and expressed willingness to make behavioral changes in response to such data.

\section{Materials and Methods}

\section{Participants}

An anonymous, approximately 25 -min, online survey was administered to 417 adolescents aged 14-17. Participants were recruited by Touchstone Research Inc. (TSR), a professional research firm that has assembled an online, double opt-in, Internet-based "Kids and Family" panel (http://touchstoneresearch.com/youthfamilies/). TSR invited a sample of US parent of teenagers to consent to their child's participation in the study. A sample of teenagers, nationally representative for gender, race, ethnicity, and geographic region and with equal age distribution (14-15 vs. 16-17 years) was then invited to assent. If teenage participants agreed, they were randomized to read one of 2 handouts about factors contributing to the development of psychiatric disorders (see further information about the handouts below). Both parental consent and adolescents' assent were obtained after they were provided with information about the study, including a simple-language explanation of key terms ("genetics" and "mental illness"). Parents were asked to indicate their demographic information (e.g., age, sex, race/ethnicity, and education) and their child's sex and age. 


\section{Study Design and Instruments}

The survey began with 4 questions assessing participants' characteristics as decision-makers (e.g., perceived ability to handle unforeseen situations), especially in health-related contexts (see further information below). Participants were then randomly assigned to one of the 2 handouts and asked to confirm that they read it before being allowed to continue the survey. Post-intervention questions explored participants' views on causal attribution of psychiatric disorders to genetics and environment, willingness to make behavioral changes, perceived control of health outcomes, and perceived utility of the information. Participants were asked to respond to the questions about willingness to make behavioral changes, perceived control of health outcomes, and perceived utility of the information having in mind the material that they read in the handout about genetic and environmental contributions to psychiatric conditions. TSR administered the survey and offered participants the equivalent of USD 10 (in points redeemable for cash or e-reward) for their participation. The researchers did not have access to participants' identifying information.

The handout that participants read was titled either "Genetics, Environment and Mental Illness," which provided extensive explanation of gene-environment interactions and their contributions to psychiatric conditions ("GxE handout"), or "Genetics and Mental Illness," which centered primarily on genetic contributions to psychiatric conditions ("psychiatric genetics handout"). The GxE handout was based on educational material previously developed by a member of the team in collaboration with service users, which has been used both clinically and in previous studies [24]. It included explanations of how both genetics and environment interact and contribute to mental illnesses and of the steps that can be taken to reduce the likelihood of or support recovery from an episode of mental illness. Psychiatric genetics was described in general terms ("genetic factors contributing to mental illness"), and environmental factors that increase the risk for the development of psychiatric conditions included, for example, stressful life events and use of drugs such as marijuana or cocaine. In addition, the $\mathrm{GxE}$ handout provided measures that individuals can take to mitigate their risk and to help recovery, including "taking medication as suggested by a doctor" and a list of "protective factors," that is, reducing stress, good sleep hygiene, healthy diet, having a good support system, and avoiding drugs like marijuana and cocaine. The explanations were supported by images that portrayed the interaction between genetics and environments [24]. The psychiatric genetics handout was developed by the research team based on existing literature. It had a prominent focus on the contribution of genetics to mental illnesses, including the genetic complexity of such conditions, while following as much as possible the structure, wording, and images of the GxE handout. Description of the genetic factors that increase the risk for developing psychiatric conditions included, for example, studies associating changes in the gene DRD2 with disorders including schizophrenia, posttraumatic stress disorder, and addiction. Environmental factors were not mentioned, although we included the possible use of prescribed medication and the list of "protective factors" described above. Both handouts and all other study material were at a 7-8th grade (13-14 year-old) reading level, assessed using Word's Flesch Kincaid Grade Level test (see online suppl. materials 1, 2; for all online suppl. material, see www.karger.com/doi/10.1159/000512475).

Two additional steps were taken to ensure that the study was adolescent-friendly. First, 3 educators with extensive experience teaching teenagers reviewed the material and provided feedback on its comprehensibility for teenagers. Changes were made to address their comments. Using the revised material, we then conducted four $1-\mathrm{h}$, online cognitive interviews with teenagers ( 2 girls, 2 boys, recruited and hosted by TSR, following the consent procedures above and offering interviewees the equivalent of USD 40 for their participation), with both the interviewee and interviewer seeing the material on a shared screen. Interviewees received the study material in advance and were asked to read it in preparation for their interview. Changes to wording and images in the material were made in light of interviewees' feedback. The final handouts were estimated to require $10 \mathrm{~min}$ to read. We hypothesized that information about the genetic and environmental contributions to psychiatric disorders (the GxE handout) would be a stronger motivator of expressed willingness to engage in risk-reducing behavioral change among adolescents than information about the genetic contributions alone (the psychiatric genetics handout) because of the strong focus on environmental factors and measures that they can adopt to mitigate the risk and to help recovery. Since the psychiatric genetics handout provided only a partial explanation of the factors contributing to psychiatric conditions, participants who were assigned to read this handout were debriefed at the end of the survey, given a link to the GxE handout, and required to confirm having read it before final completion of the survey.

\section{Measures}

Participants' characteristics as decision-makers: The survey included 4 validated scales that have been shown to be associated with health outcomes: participants' self-efficacy, that is, "personal competence to deal effectively with a variety of stressful situations," [25] health empowerment [26], intolerance of uncertainty [27], and sensation-seeking [28]. Higher scores indicate higher levels of all 4 traits.

The scales were adjusted to the study's focus on mental health and to ensure they were adolescent-friendly as described above. The self-efficacy scales included 10 statements, such as "If I am in trouble, I can usually think of a solution." The 8-item health empowerment scale included statements such as "I know what helps me stay motivated to care for my health." The intolerance of uncertainty scale comprised 12 statements, such as "Unforeseen events upset me greatly." The 8-item sensation-seeking scale included, for example, "I would love to have new and exciting experiences, even if they are illegal." The response options for each statement were on a 1-4 (i.e., self-efficacy scale) or 1-5 Likert scale ( 1 = least agreement). Significantly, only minor changes in wording were made in these previously validated scales (e.g., changing the word "efficient" to "well" or "acting" to "doing something"). Cronbach's alpha for the modified scales indicates high internal consistency (ranging from 0.81 to 0.88 ).

Causal attribution of psychiatric disorders to genetics and environments was assessed by 2 questions: "How much do you think mental illness is caused by genetic factors?" (Likert scale $1-5 ; 1=$ "Genetics does not contribute at all to mental illness"; 5 = "Genetics alone causes mental illness") and "How much do you think mental illness is caused by experiences, such as things that happened to someone, or environmental factors?" (Likert scale 1-5; 1 = "Experiences do not contribute at all"; 5 = "Experiences alone cause mental illness").

Willingness to make behavioral changes. Participants were instructed to "[Imagine] that you were told that you have a large
Sabatello/Chen/Herrera/Brockhoff/ Austin/Appelbaum 
Table 1. Participants' sociodemographic characteristics

\begin{tabular}{|c|c|c|c|}
\hline & $\begin{array}{l}\text { Total } \\
(N=417)\end{array}$ & $\begin{array}{l}\text { Psychiatric } \\
\text { genetics } \\
\text { handout } \\
(N=216)\end{array}$ & $\begin{array}{l}\mathrm{GxE} \\
\text { handout } \\
(N=201)\end{array}$ \\
\hline \multicolumn{4}{|l|}{ Gender, $n(\%)$} \\
\hline Female & $213(51.1)$ & $109(50.5)$ & $104(51.7)$ \\
\hline Male & $204(48.9)$ & $107(49.5)$ & $97(48.3)$ \\
\hline \multicolumn{4}{|l|}{ Age, $n(\%)$} \\
\hline $14-15$ years & $214(51.3)$ & $108(50)$ & $106(52.7)$ \\
\hline $16-17$ years & $203(48.7)$ & $108(50)$ & $95(47.3)$ \\
\hline \multicolumn{4}{|l|}{ Ethnicity, $n(\%)$} \\
\hline Hispanic & $94(22.5)$ & $48(51.1)$ & $46(48.9)$ \\
\hline Non-Hispanic & $323(77.5)$ & $168(52)$ & $155(48)$ \\
\hline \multicolumn{4}{|l|}{ Race, $n(\%)$} \\
\hline Black/African American & $58(13.9)$ & $34(15.7)$ & $25(12.4)$ \\
\hline White & $322(77.2)$ & $120(55.6)$ & $112(55.7)$ \\
\hline Asian & $22(5.3)$ & $11(5.1)$ & $15(7.5)$ \\
\hline American Indians/Alaska Natives & $9(2.2)$ & $3(1.4)$ & $6(3)$ \\
\hline Native Hawaiian/other Pacific Islanders & $6(1.4)$ & $4(1.9)$ & $2(1)$ \\
\hline \multicolumn{4}{|l|}{ Family income (parent report), $n(\%)$} \\
\hline USD $\leq 19,999$ & $29(7)$ & $17(7.9)$ & $12(6)$ \\
\hline USD 20,000-44,999 & $88(21.1)$ & $44(20.4)$ & $44(21.8)$ \\
\hline USD 45,000-74,999 & $121(29)$ & $62(28.7)$ & $59(29.4)$ \\
\hline $\mathrm{USD} \geq 75,000$ & $179(42.9)$ & $77(35.7)$ & $86(42.8)$ \\
\hline \multicolumn{4}{|l|}{ Parental education, $n(\%)$} \\
\hline Less than high school & $3(0.7)$ & $1(0.5)$ & $2(1)$ \\
\hline High school diploma & $66(15.8)$ & $35(16.2)$ & $31(15.4)$ \\
\hline Some college/technical/vocational school & $103(24.7)$ & $53(24.5)$ & $50(24.9)$ \\
\hline Undergraduate college/technical/vocational school degree & $148(35.5)$ & $76(35.2)$ & $72(35.8)$ \\
\hline Graduate degree & $72(17.3)$ & $41(19)$ & $31(15.4)$ \\
\hline
\end{tabular}

number of factors contributing to mental illness," and asked: "Would you do any of the following?" listing 8 statements about behaviors that could reduce the risk of developing a psychiatric condition (e.g., "Pay more attention to eating healthy," "Avoid or reduce taking drugs like marijuana and cocaine"). Response options were yes/no ( 1 = "no," 2 = "yes").

Perceived control of health outcomes was measured using 2 items, adjusted from a study on direct-to-consumer genomic testing to focus on mental health [29]. Participants were asked to think about the handout that they read and to state their degree of agreement with each of the following statements: "Changes in lifestyle, diet, and exercise can reduce a person's chances of developing mental illness and improve outcomes," and "Mental health support and treatment can reduce a person's chances of developing mental illness and improve outcomes" (5-point Likert scale, $1=$ least agreement).

Perceived utility of the information was assessed by 2 items ("The handout provided me with new information" and "The handout provided me with important information"). Participants were then asked to "[Think] about the factors that contribute to the development of mental illness," and indicate their level of agreement with statements relating to "why it would be important for you to know this information" (8 items) and "why would it be important for you NOT to know this information" (3 items). These questions were developed based on the existing literature. Example of statements in favor of knowing was "I would be able to take better care of myself." The statements in favor of not knowing were "I am too young for this information," "I wouldn't change anything I do anyway," and "Knowing this information may make me anxious or be too stressful." The response options for all the perceived utility questions were on a 1-5 Likert scale ( 1 = least agreement).

\section{Statistical Analysis}

Study data were analyzed using SAS 9.4 and SPSS (IBM) 24.0. Descriptive statistics were used for demographic characteristics. Mean and standard deviation (SD) were used to measure participants' characteristics as decision-makers (i.e., self-efficacy, health empowerment, intolerance to uncertainty, and sensation-seeking scores). $T$ tests for continuous measures and $\chi^{2}$ tests for categorical measures were used to determine differences between the 2 intervention groups. Generalized linear regression models were used to assess the impact of demographic covariates (age, gender, and race/ethnicity) and participants' characteristics as decision-mak- 
Table 2. Participants' decision-making characteristics

\begin{tabular}{|c|c|c|c|c|c|c|}
\hline & $\begin{array}{l}\text { Overall } \\
(n=417) \\
\text { mean (SD) }\end{array}$ & $\begin{array}{l}\text { Psychiatric genetics } \\
(n=216) \\
\text { mean (SD) }\end{array}$ & $\begin{array}{l}\text { GxE } \\
(n=201) \\
\text { mean (SD) }\end{array}$ & Estimate* & $95 \% \mathrm{CI}^{*}$ & $p$ value* \\
\hline Health empowerment & $31.8(5.2)$ & $31.8(5.4)$ & $31.77(4.9)$ & 0.08 & -0.94 to 1.09 & 0.8847 \\
\hline Intolerance of uncertainty & $35.1(9.5)$ & $34.8(9.9)$ & $35.33(9.0)$ & -0.47 & -2.31 to 1.36 & 0.6140 \\
\hline Sensation-seeking behavior & $21.9(7.0)$ & $22.0(7.2)$ & $21.8(6.8)$ & 0.13 & -1.23 to 1.49 & 0.8494 \\
\hline
\end{tabular}

GxE, gene-environment interaction. * From GLM, models by intervention groups, controlling for age, gender, race, and ethnicity.

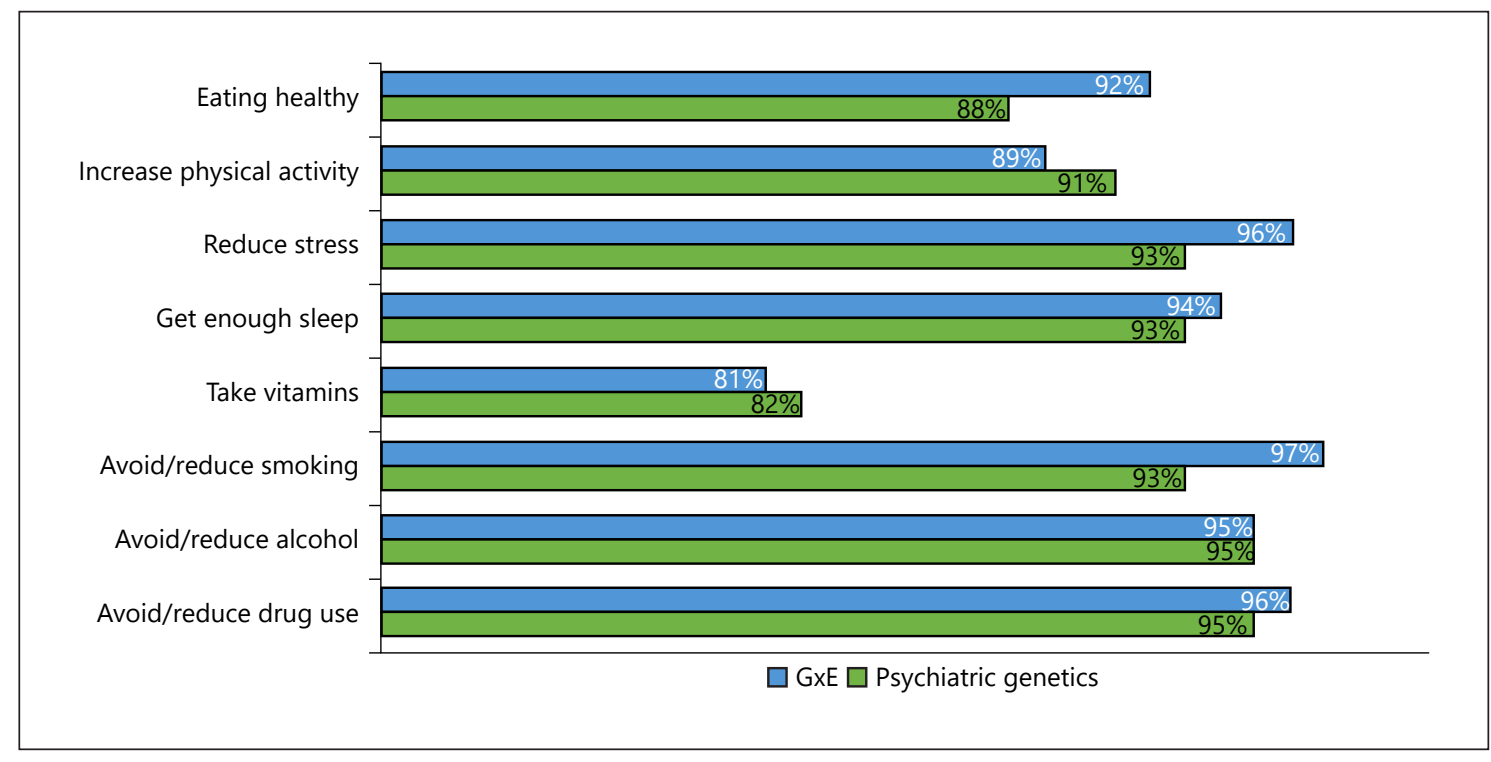

Fig. 1. Participants' expressed willingness to make behavioral changes if told they have a large number of risk factors. GxE, gene-environment interaction.

ers on responses to the post-intervention survey. Participants' age was collapsed into 14- to 15-year olds and 16- to 17-year olds to increase the power of the analysis. A $p$ value $<0.05$ was considered significant.

\section{Results}

\section{Participants' Characteristics}

Demographic characteristics are provided in Table 1; 417 teenagers completed the survey, of whom 51\% were of age $14-15$ years and 49\% 16-17. Among them, 51\% were female and 49\% male, 23\% identified as Hispanic, $77 \%$ as white, 14\% black/African American, 5\% Asian, and 4\% American Indians/Alaska Native and Native Hawaiian/other Pacific Islander. Of them, 57\% had a house- hold annual income USD $\leq 74,999$ (the 2017 mean income in the US was USD 77,713 [30]), and 201 (48\%) participants received the GxE handout and 216 (52\%) received the psychiatric genetics handout. No differences in mean scores of demographic or decision-making characteristics were found between the intervention groups ( $\mathrm{Ta}$ ble 2).

\section{Causal Attribution of Psychiatric Disorders to \\ Genetics and Environments}

In total, $95 \%$ of participants thought that genetics contributes at least moderately to mental illness (mean $=3.4$, $\mathrm{SD}=0.7$ ) and $89 \%$ thought that experiences contribute at least moderately to mental illness (mean $=3.3, \mathrm{SD}=0.9$ ). Significant differences were found between the intervention groups with respect to casual attributions. Partici-
18

Public Health Genomics 2021;24:14-25 DOI: 10.1159/000512475
Sabatello/Chen/Herrera/Brockhoff/ Austin/Appelbaum 
Table 3. Participants' responses to the questions about the importance (or not) of knowing risk information

\begin{tabular}{|c|c|c|c|c|c|c|c|c|c|}
\hline & $\begin{array}{l}\text { agree/ } \\
\text { strongly } \\
\text { agree }(\%)\end{array}$ & $\begin{array}{l}\text { mean } \\
(\mathrm{SD})\end{array}$ & $\begin{array}{l}\text { agree/ } \\
\text { strongly } \\
\text { agree }(\%)\end{array}$ & $\begin{array}{l}\text { mean } \\
(\mathrm{SD})\end{array}$ & $\begin{array}{l}\text { agree/ } \\
\text { strongly } \\
\text { agree }(\%)\end{array}$ & $\begin{array}{l}\text { mean } \\
(\mathrm{SD})\end{array}$ & Estimate & $95 \% \mathrm{CI}$ & $\begin{array}{l}p \\
\text { value* }\end{array}$ \\
\hline \multicolumn{10}{|l|}{ Why would it be important for you to know this information? } \\
\hline $\begin{array}{l}\text { I would be able to change behaviors that increase my risk } \\
\text { to develop a mental illness, such as using drugs or drinking } \\
\text { alcohol }\end{array}$ & 82.2 & $4.3(0.9)$ & 83.3 & $4.3(0.9)$ & 81.1 & $4.2(1.0)$ & 0.11 & $\begin{array}{l}(-0.07 \\
0.29)\end{array}$ & 0.232 \\
\hline It would make it easier for me to get the support that I need & 75.6 & $4.1(1.0)$ & 76.0 & $4.1(1.0)$ & 75.1 & $4.1(1.0)$ & 0.05 & $\begin{array}{l}(-0.14 \\
0.24)\end{array}$ & 0.600 \\
\hline $\begin{array}{l}\text { I would be able to make better decisions about having } \\
\text { children in the future }\end{array}$ & 61.9 & $3.8(1.1)$ & 59.8 & $3.8(1.1)$ & 64.2 & $3.8(1.1)$ & 0.02 & $\begin{array}{l}(-0.19 \\
0.23)\end{array}$ & 0.876 \\
\hline $\begin{array}{l}\text { It would allow my family members to take better care of } \\
\text { themselves }\end{array}$ & 74.8 & $4.1(1.0)$ & 77.8 & $4.1(1.0)$ & 71.6 & $4(1.0)$ & 0.10 & $\begin{array}{l}(-0.1 \\
0.29)\end{array}$ & 0.332 \\
\hline Having information is always good & 93.0 & $4.6(0.7)$ & 93.1 & $4.6(0.6)$ & 93.0 & $4.6(0.7)$ & 0.01 & $\begin{array}{l}(-0.12 \\
0.14)\end{array}$ & 0.912 \\
\hline \multicolumn{10}{|l|}{ Why would it be important for you NOT to know this information? } \\
\hline I am too young for this information & 8.4 & $1.7(1.1)$ & 10.2 & $1.7(1.1)$ & 6.5 & $1.6(1.0)$ & 0.08 & $\begin{array}{l}(-0.13 \\
0.28)\end{array}$ & 0.462 \\
\hline I would not change anything I do anyway & 15.6 & $2.2(1.2)$ & 18.1 & $2.2(1.3)$ & 13.0 & $2.1(1.2)$ & 0.11 & $\begin{array}{l}(-0.13 \\
0.35)\end{array}$ & 0.354 \\
\hline
\end{tabular}

* $p$ value assessed differences in the mean score between participants in the intervention groups.

pants who read the psychiatric genetics handout were more likely to think that psychiatric disorders are caused by genetic factors than those who read the $\mathrm{GxE}$ handout $(t=-2.21, \mathrm{df}=415, p=0.028)$.

\section{Willingness to Make Behavioral Changes (Fig. 1)}

For each of the items, a large majority of participants stated that if told that they had a large number of risk factors contributing to psychiatric conditions, they would make behavioral changes (range from $81 \%$ for "Make sure I take vitamins" [mean $=1.8, \mathrm{SD}=0.4$ ] to $95 \%$ for "Avoid or reduce taking drugs like marijuana and cocaine" $[$ mean $=2.0, \mathrm{SD}=0.2]$ ). Contrary to our hypothesis, no differences were found between the intervention groups.

Teenagers and Precision Psychiatry

\section{Perceived Control of Health Outcomes}

Most participants agreed or strongly agreed that "Changes in lifestyle, diet, and exercise can reduce a person's chances of developing mental illness and improve outcomes" $(77 \%$; mean $=4.1, \mathrm{SD}=1.0)$ and that "Mental health support and treatment can reduce a person's chances of developing mental illness and improve outcomes" $(81 \%$; mean $=4.2, \mathrm{SD}=0.9)$. No significant differences were found between the intervention groups.

\section{Perceived Utility}

In total, $85 \%$ of participants agreed/strongly agreed that the handout provided them with new information (mean $=4.34, \mathrm{SD}=0.93$ ) and $90 \%$ reported that the hand- 
Table 4. Impact of participants' characteristics as decision-makers on post-intervention responses to survey*

\begin{tabular}{|c|c|c|c|c|c|c|c|c|c|c|c|c|}
\hline & \multicolumn{3}{|c|}{ Self-efficacy } & \multicolumn{3}{|c|}{ Health empowerment } & \multicolumn{3}{|c|}{ Intolerance of uncertainty } & \multicolumn{3}{|c|}{ Sensation-seeking } \\
\hline & estimate & $95 \% \mathrm{CI}$ & $p$ value & estimate & $95 \% \mathrm{CI}$ & $p$ value & Estimate & $95 \% \mathrm{CI}$ & $p$ value & estimate & $95 \% \mathrm{CI}$ & $p$ value \\
\hline $\begin{array}{l}\text { Importance of knowing the factors contributing } \\
\text { to the development of mental illness }\end{array}$ & 0.02 & $(-0.14,0.17)$ & 0.8032 & 0.51 & $(0.37,0.64)$ & $<0.001$ & 0.06 & $(0.01,0.12)$ & 0.0130 & 0.03 & $(-0.04,0.1)$ & 0.3707 \\
\hline $\begin{array}{l}\text { Importance of NOT knowing the factors } \\
\text { contributing to the development of mental illness }\end{array}$ & 0.02 & $(-0.05,0.09)$ & 0.5524 & -0.08 & $(-0.15,-0.02)$ & 0.0127 & 0.07 & $(0.04,0.11)$ & 0.0001 & 0.04 & $(0,0.08)$ & 0.0519 \\
\hline Perceived control & 0.04 & $(0,0.09)$ & 0.0733 & 0.08 & $(0.04,0.12)$ & 0.0002 & 0.01 & $(-0.01,0.03)$ & 0.3048 & 0.03 & $(0,0.05)$ & 0.0183 \\
\hline Willingness to make behavioral changes & -0.01 & $(-0.05,0.03)$ & 0.5921 & 0.06 & $(0.03,0.09)$ & 0.0001 & 0.00 & $(-0.01,0.01)$ & 0.5990 & -0.01 & $(-0.03,0.01)$ & 0.1794 \\
\hline
\end{tabular}

out provided them with important information (mean $=$ $4.44, \mathrm{SD}=0.84$ ). No significant differences between the 2 intervention groups were found for these questions.

Responses to the questions on the importance of knowing about their risks for mental disorders are provided in Table 3. At least three-quarters of participants agreed or strongly agreed that "Information is always good" (93\%), followed by "I would be able to take better care of myself" (84\%), "I would be able to change behaviors that increase my risk to develop a mental illness, such as using drugs or drinking alcohol" (82\%), and "It would make it easier for me to get the support that I need" (76\%) (the means for these statements $\geq 4.1, \mathrm{SD} \leq 1.1$ ). The least selected option was "I would be able to make better decisions about having children in the future" $(62 \%$, mean $=$ $3.8, \mathrm{SD}=1.1)$. No significant differences were found between the intervention groups.

With regard to reasons in favor of not knowing this information, only a small minority of participants agreed or strongly agreed with the statements, "I am too young for this information" ( $8 \%$; mean $=1.7, \mathrm{SD}=1.1)$, "I wouldn't change anything I do anyway" (16\%; mean score $=2.2, \mathrm{SD}=1.2$ ), and "Knowing this information may make me anxious or be too stressful" (15\%; mean = $2.1, \mathrm{SD}=1.2$ ) (Table 3). No significant differences were found between the intervention groups.

\section{Impact of Covariates on Postintervention Responses}

Participants' demographic characteristics (age, gender, and race/ethnicity) had no impact on responses to post-intervention questions (i.e., causal attribution of psychiatric disorders to genetics and environments, perceived utility of the information, perceived control of health outcomes, and willingness to make behavioral changes). However, participants' characteristics as decision-makers impacted most of the post-intervention responses (Table 4). Higher health empowerment scores were positively associated with statements in favor of knowing the information (Estimate $=0.51,95 \%$ CI: 0.37 $0.64, p<0.0001$ ), perceived control over mental health outcomes (Estimate $=0.08,95 \%$ CI: $0.04-0.12, p=$ 0.0002), and expressed willingness to make behavioral changes to reduce risk for psychiatric conditions (Estimate $=0.06,95 \%$ CI: $0.03-0.09, p=0.0001$ ), but negatively associated with statements against knowing this information (Estimate $=-0.08,95 \% \mathrm{CI}:-0.15$ to -0.02 , $p=0.0127)$. Higher intolerance of uncertainty scores were positively associated with statements in favor of knowing the information about how to improve self-care as well as with concerns about having this knowledge, for example, due to young age or possible increase in anxiety (respectively, Estimate $=0.06,95 \%$ CI: 0.01-0.12, $p=$ 0.0130; Estimate $=0.07,95 \%$ CI: 0.04-0.11, $p<0.0001$ ). Higher sensation-seeking scores were positively associated with perceived control over mental health outcomes (Estimate $=0.03,95 \%$ CI: $0-0.05, p=0.0183$ ). These associations remained significant when adjusted for participants' demographic characteristics, with the additional finding that 14- to 15 -year olds were less likely than 16- to 17-year olds to believe that they have control over mental health outcomes (Estimate $=-0.49,95 \%$ CI: -0.80 to $-0.17, p=0.0024)$.

\section{Discussion}

As studies indicate that $20 \%$ of American teens have a diagnosable psychiatric condition and that the social, health care, and monetary costs associated with childhood psychiatric conditions commonly endure into adulthood [31], teenagers are - or should be - central to precision psychiatry's efforts to reduce the occurrence of psychiatric conditions. As a group, teenagers are prone to risk-taking behaviors that may increase the likelihood of 
developing psychiatric conditions (e.g., substance use) [32], but may also be more amenable than adults to changes in health practices that may mitigate those risks [33]. However, only a few studies exist on teenagers in genomic contexts, and none of them focused on precision psychiatry, a critical arena for precision medicine, and translational genomic efforts.

Our study explored the views of teenagers from the general public about their interest in and willingness to make behavioral changes in light of information about genetic and environmental factors contributing to psychiatric disorders. Although recruitment through a survey-research company's online panel may have introduced bias, the selection of a nationally representative sample somewhat reduces the concern. By randomizing the handout that participants read, our study aimed to identify whether the provision of information that focuses mostly on the genetic underpinnings of psychiatric conditions would yield different attitudes among teenagers than information that explains the interaction between genetics and environments, suggesting a greater degree of human agency and control.

The overwhelming majority of participants in our study stated that the handout they read provided new and important information. They highly valued having the information and believed that knowing this information would enable them to take better care of themselves, to make behavioral changes to reduce their risk of developing a psychiatric condition, and to seek support that they may need. Only a minority of participants thought that they were too young for this information, that the information would be too anxiety provoking, or that they would not make behavioral changes despite such information. These findings were not impacted by participants' demographic characteristics, indicating broad acknowledgement of the benefits of learning about this issue.

However, the handouts provided - psychiatric genetics or $\mathrm{GxE}$ - did not impact participants' responses as we expected. It is possible that the reference to some protective measures to reduce risk or support recovery in the psychiatric genetics handout affected this outcome, though a handout that described genetics as the sole contributor to psychiatric disorders would have been misleading and thus unethical to give to participants. It is also possible that the overall high expressed willingness to make behavioral changes overshadowed the exact content of the information that participants read. Nonetheless, the finding that those who read the psychiatric genetics handout were more likely to attribute psychiatric dis-

Teenagers and Precision Psychiatry orders to genetics highlights the importance of how risk information is framed and communicated. Although most people are unlikely to endorse an entirely genetic deterministic approach to health outcomes [34], especially psychiatric conditions [35], deterministic narratives of precision psychiatry may impact how adolescents conceptualize such conditions.

A major finding of our study is the role of empowerment in translational genomics. Teenagers who viewed themselves as empowered decision-makers were more likely to engage in each critical aspect of precision psychiatry, from expressing an interest in information about individual risk factors, to expressed willingness to make behavioral changes, and perceived control over their mental health outcomes. This is not surprising. Studies of adults have long suggested that empowerment is central to achieving positive mental health and improving health behaviors, as well as management and quality of mental health care and outcomes [36]. Similarly, teenagers' empowerment has been shown to be associated with higher perceived health among teenagers [37], increased self-efficacy, perceived personal control, and overall mental health outcomes [36, 38].

This finding is reassuring for translational genomics efforts in psychiatry, but research is needed to allow for better understanding of how to facilitate a sense of empowerment among teenagers learning about their psychiatric genetic predispositions. Studies with adults (mostly patients) in Canada have found that psychiatric genetic counseling can be empowering. Adults participating in such sessions found the educational and support components of genetic counseling to be useful for managing uncertainty and reducing feelings of guilt and stigma and expressed motivation in some cases to make behavioral changes following the genetic counseling session [39]. However, it is unclear whether these outcomes can be replicated elsewhere [40]. Research shows that many genetic counselors are uncomfortable discussing psychiatric genetics with patients $[41,42]$ and have negative attitudes toward individuals with such conditions [43], and that, though it is a growing discipline, psychiatric genetic counseling is - as yet - neither routinely nor widely offered [44]. Although efforts to rectify these issues are underway, the challenges are compounded in the USA, where the health-care settings are markedly different than those in the Canadian clinics, including the latter's national health-care coverage and unique training of genetic counselors who provide this service [24].

Precision medicine, including precision psychiatry, adds complexities to the prospect of teenagers' empower- 
ment in genomic-related decisions. Parents, teenagers, and health-care professionals may disagree about the value of empowering teenagers as genomic decision-makers and the appropriate balance between parents' and teenagers' interests in learning about their psychiatric genomic risks [45]. Although clinicians can facilitate teenagers' empowerment in health contexts, studies indicate that their knowledge of genomics, especially of psychiatric genetics and gene-environment interactions, is limited [40, $41,46,47]$. These issues are unlikely to lessen with the growing research on prediction of genetic risk for psychiatric conditions (e.g., polygenic risk scores); on the contrary, a growing body of complex information may increase the possibility of misunderstanding and misinterpretation [48]. Improving public understanding of the potential benefits of precision psychiatry and stakeholders' psychiatric genomic knowledge will move the needle in the right direction. However, engaging teenagers in conversations about precision psychiatry - ideally through psychiatric genetic counseling $[40,49]$ - will be key for developing teenager-friendly interventions. As a starting point, these conversations should include ethical and legal considerations of teenagers' autonomy, possible harms and benefits arising from psychiatric genetic data, and universal accessibility to services that support behavioral change $[45,49]$.

Better understanding of the various aspects of empowerment that are important for teenagers is also needed but understudied in this context. As scholars have observed, empowerment is a complex, multilevel construct with no consensual definition. Some conceptualize it as an active, continuous process that can occur at the individual, interpersonal, and community levels; others view empowerment as an outcome that displays itself differently across fields (e.g., social contexts and educational settings) and that can be better identified when it is weak or absent rather than when it is present $[50,51]$. Moreover, although there is agreement that empowerment includes some aspects of gaining control over a particular life context, there are different views regarding how such power is acquired, who should be entrusted with facilitating this transformation (e.g., parents, educators, and peers), and what the best ways are for doing that (e.g., instructional, experiential learning, and teenager-adult dialog) $[37,50]$.

In precision psychiatry, interpersonal- and community-level empowerment are likely to have a significant impact on teenagers' engagement in genomic conversations. For instance, studies show that teachers can play as important roles as parents in empowering teenagers to make healthy choices, including in the context of mental health
$[37,52]$, but also that existing curricula in schools are not up-to-date with existing knowledge of genomics [53]. As empowerment is a relational process [54], teens' and their families' and communities' experiences of social marginalization (e.g., poverty, which is disproportionally high among underserved racial/ethnic minorities [55]), and bias in health care may affect their engagement in genomic discussions, as found in studies of African American and Latino adults [56-60]. Stigma surrounding psychiatric genetics and teenagers' experiences with psychiatric conditions (personally or through family history) may further affect the degree of empowerment and extent of supports they need. Identifying what these may entail for precision psychiatry and knowledge as to how teenagers conceptualize empowerment in precision psychiatry will be needed.

Similarly, the implementation of precision psychiatry across racial and ethnic groups may require caution and tailored approaches to empower teenagers from historically marginalized communities. Importantly, our study found high interest in information and willingness to make behavioral changes in light of psychiatric genetic predispositions regardless teenagers' race/ethnicity. However, the ability of teenagers from historically marginalized racial/ethnic communities to enjoy the benefits of translational genomic efforts is likely to be significantly different than that of White teens. As is well-established, biobank and genomic cohorts are overwhelmingly white, resulting in insufficient power to identify complex genetic interactions and polygenic risk scores for racial/ ethnic minorities, including for psychiatric conditions [48]. Concurrently, distrust in the medical community has been recognized as a barrier to accessing genomic medicine among African American, Latino, and Indigenous populations $[61,62]$. For translational genomic efforts in psychiatry to materialize, it will be necessary to increase cohort diversity in genomic research and to address the barriers. Given that experience with psychiatric genetic counseling to date has been predominantly with white adults [39], it will also be necessary to engage with teenagers and families across racial/ethnic groups to ensure that methods of engagement and supports are tailored to their sociocultural needs [33].

Our findings that participants with higher intolerance of uncertainty expressed more support for knowing the information but also more concerns about having it are consistent with earlier research and calls for caution. Studies indicate that stakeholders in health care are uncomfortable with genomic uncertainty. Health-care professionals express uneasiness about returning inconclu-
Public Health Genomics 2021;24:14-25 DOI: $10.1159 / 000512475$
Sabatello/Chen/Herrera/Brockhoff/ Austin/Appelbaum 
sive genetic results $[40,63]$, and patients express fear, anxiety and frustration when genetic results are inconclusive [64]. Similarly, a study of 14- to 25-year-olds with family histories of Huntington disease $(n=8)$ found that many experience the uncertainty before testing to be a greater barrier to moving forward with their life than learning about negative or positive results [65]. Although studies indicate that teenagers are less ambiguity-averse than adults [66], our findings highlight the need for individual assessment: at least some teenagers in our study expressed higher intolerance of uncertainty, which was associated with greater concerns about having information about psychiatric genetics. It will be important to ensure that teenagers (and their parents) are informed about this risk and offered measures to mediate the challenge.

Future research can help in closing these gaps. It could explore areas of contention in the triangle of parents, teenagers and clinicians involved in precision psychiatry and identify teenagers' needs and preferences regarding the best enablers of empowerment (e.g., genetic counselors, teachers). Similarly, exploring the long-term impact of psychiatric genomic interventions (e.g., genetic counseling [24]) on risk-reducing behaviors among adolescents, especially those from families with psychiatric disorders, would be invaluable given that studies with adults found limited impact of genomic data on actual behaviors [67]. Research should also explore the challenges experienced by potential enablers of empowerment (e.g., teachers) and identify measures to address these concerns to ensure that teenagers across racial and ethnic groups can be part of the conversation.

\section{Limitations}

This study has several limitations. First, due to IRB concerns, we did not collect data about participants' family histories of psychiatric conditions or their previous experiences with psychiatric genetics, precluding analyses of the effect of these factors on participants' responses. Nor did we assess knowledge of psychiatric genetics, as such knowledge is unlikely among this age-group. Additionally, participants were recruited through TSR's Internet-based "Kids and Family" panel. Although this selfselected panel may have introduced some bias, the sample was selected to assure national representation as described above. Finally, given the hypothetical nature of the survey, it is impossible to know whether adolescents' expressed interest and responses will translate into actual behavioral changes if they receive information about their personal psychiatric genetic risks. Further research can address these issues.

Teenagers and Precision Psychiatry

\section{Conclusion}

Although precision psychiatry is only in its infancy, prevention should be a major component of this effort. Notwithstanding common perceptions of adolescents as unpredictable, impulsive risk-takers, involving teenagers in these discussions will be key.

Our study of teenagers from the general population is a first step in this direction. We found high interest among this age-group in information about genetic and environmental factors contributing to psychiatric disorders and expressed willingness to make a range of behavioral changes to reduce their risks for such conditions. Although our findings only indicate teenagers' stated interest and intentions to change behaviors, they highlight the need for identifying the measures that can empower teenagers to act on their psychiatric risk factors.

As teenagers' autonomy and competence are increasingly recognized in health-related settings $[45,46]$ the newly emerging health-care model of precision psychiatry should lead the way. This model, which if implemented correctly, requires a non-reductive biological explanation of psychiatric conditions, is more responsive to the socioenvironmental and lifestyle factors that affect teenagers' (and adults') mental health outcomes, and can provide empowering tools to mitigate genetic risks. Engagement and research with this age-group are urgently needed to allow adolescents, especially those with family histories of psychiatric conditions, to optimize their mental health trajectory, including by reaping of the benefits of precision psychiatry.

\section{Acknowledgements}

This work was supported by NHGRI grants K01HG008653 and RM1HG007257 and Columbia University's Precision Medicine \& Society Pilot Grant Program (grant UR002680). We thank the anonymous teenager reviewers as well as Cochava Branigan, MS Ed, Cassius Gil, MS Ed, and Coy Daily, MS Ed, for their comments and insights as educators on the study material.

\section{Statement of Ethics}

The IRB at the NY State Psychiatric Institute approved the study (protocol \#7648). Both parental consent and adolescents' assent were obtained. 


\section{Conflict of Interest Statement}

Maya Sabatello is a member of the All of Us Research Program's Institutional Review Board. The authors declare no other conflict of interest.

\section{Funding Sources}

This work was supported by NHGRI grants K01HG008653 and RM1HG007257 and Columbia University's Precision Medicine \& Society Pilot Grant Program (grant UR002680).

\section{Author Contributions}

Maya Sabatello conceived the notion of this project, co-designed the study, led the acquisition, analysis, interpretation of the data, contributed to the funding for the project, prepared the initial draft, and revised the manuscript for submission. Ying Chen contributed largely to data analysis and interpretation. Carmen Fiorella Herrera contributed to the data collection, research, and investigation process. Erika Brockhoff contributed to the data collection, research, and investigation process. Jehannine Austin co-designed the study, made significant contributions to the development of study material, funding for the project, and critical review of the manuscript. Paul S. Appelbaum co-designed the study, made significant contributions to the study material, funding for the project, and critical review of the manuscript. All authors gave final approval of the version to be published.

\section{References}

1 Fernandes BS, Williams LM, Steiner J, Leboyer M, Carvalho AF, Berk M. The new field of "precision psychiatry". BMC Med. 2017; 15(1):80.

2 Dunn EC, Brown RC, Dai Y, Rosand J, Nugent NR, Amstadter AB, et al. Genetic determinants of depression: recent findings and future directions. Harv Rev Psychiatry. 2015; 23(1):1-18

3 Liu H, Li Y, Guo G. Gene by social-environment interaction for youth delinquency and violence: thirty-nine aggression-related genes. Soc Forces. 2015;93(3):881-903.

4 Eley TC, Sugden K, Corsico A, Gregory AM, Sham P, McGuffin P, et al. Gene-environment interaction analysis of serotonin system markers with adolescent depression. Mol Psychiatry. 2004;9(10):908-15.

5 Hines LA, Morley KI, Mackie C, Lynskey M. Genetic and environmental interplay in adolescent substance use disorders. Curr Addict Rep. 2015;2(2):122-9.

6 Sullivan PF, Agrawal A, Bulik CM, Andreassen OA, Børglum AD, Breen G, et al. Psychiatric genomics: an update and an agenda. Am J Psychiatry. 2018;175(1):15-27.

7 Hoehe MR, Morris-Rosendahl DJ. The role of genetics and genomics in clinical psychiatry. Dialogues Clin Neurosci. 2018;20(3):169-77.

8 Bousman C, Maruf AA, Müller DJ. Towards the integration of pharmacogenetics in psychiatry: a minimum, evidence-based genetic testing panel. Curr Opin Psychiatry. 2019; 32(1):7-15

9 Rees E, Owen MJ. Translating insights from neuropsychiatric genetics and genomics for precision psychiatry. Genome Med. 2020; 12(1):43.

10 Wilde A, Mitchell PB, Meiser B, Schofield PR Implications of the use of genetic tests in psychiatry, with a focus on major depressive disorder: a review. Depress Anxiety. 2013;30(3): $267-75$.

11 Attygalle UR, Perera H, Jayamanne BDW Mental health literacy in adolescents: ability to recognise problems, helpful interventions and outcomes. Child Adolesc Psychiatry Ment Health. 2017;11:38.

12 Gomes FV, Rincón-Cortés M, Grace AA. Adolescence as a period of vulnerability and intervention in schizophrenia: insights from the MAM model. Neurosci Biobehav Rev. 2016; 70:260-70.

13 Tercyak KP, Peshkin BN, Wine LA, Walker LR. Interest of adolescents in genetic testing for nicotine addiction susceptibility. Prev Med. 2006;42(1):60-5.

14 Harel A, Abuelo D, Kazura A. Adolescents and genetic testing: what do they think about it? J Adolesc Health. 2003;33(6):489-94.

15 Webster TH, Beal SJ, Brothers KB. Motivation in the age of genomics: why genetic findings of disease susceptibility might not motivate behavior change. Life Sci Soc Policy. 2013;9(1):1-15

16 Michalak EE, Suto MJ, Barnes SJ, Hou S, Lapsley S, Scott MW, et al. Effective self-management strategies for bipolar disorder: a community-engaged delphi consensus consultation study. J Affect Disord. 2016;206:7786.

17 Kadden RM, Litt MD. The role of self-efficacy in the treatment of substance use disorders. Addict Behav. 2011;36(12):1120-6.

18 Johnson NG. On treating adolescent girls: focus on strengths and resiliency in psychotherapy. J Clin Psychol. 2003;59(11):1193-203.

19 Hasan A, Musleh M. The impact of an empowerment intervention on people with schizophrenia: results of a randomized controlled trial. Int J Soc Psychiatry. 2017;63(3): $212-23$.

20 Fornaro M, De Berardis D, Iasevoli F, Pistorio ML, D'Angelo E, Mungo S, et al. Treatment adherence towards prescribed medications in bipolar-II acute depressed patients: relationship with cyclothymic temperament and "therapeutic sensation seeking" in response towards subjective intolerance to pain. J Affect Disord. 2013;151(2):596-604.
21 McAllister M, Davies L, Payne K, Nicholls S, Donnai D, MacLeod R. The emotional effects of genetic diseases: implications for clinical genetics. Am J Med Genet A. 2007;143a(22): 2651-61.

22 Sabatello M, Juengst E. Genomic essentialism: its provenance and trajectory as an anticipatory ethical concern. Hastings Cent Rep. 2019;49(Suppl 1):S10-8.

23 Gamm JL, Nussbaum RL, Bowles Biesecker B. Genetics and alcoholism among at-risk relatives II: interest and concerns about hypothetical genetic testing for alcoholism risk. Am J Med Genet A. 2004;128a(2):151-5.

24 Austin JC. Evidence-based genetic counseling for psychiatric disorders: a road map. Cold Spring Harb Perspect Med. 2020 Jun;10(6): a36608.

25 Schwarzer R, Jerusalem M. Generalized selfefficacy scale. In: Weinman J, Wright S, Johnston $\mathrm{M}$, editors. Measures in health psychology: a user's portfolio Windsor. UK: NferNelson; 1995. p. 35-7.

26 Diabetes empowerment scale 2007. Available from: http://diabetesresearch.med.umich. edu/Tools_SurveyInstruments.php\#des.

27 Carleton RN, Norton MA, Asmundson GJ. Fearing the unknown: a short version of the intolerance of uncertainty scale. J Anxiety Disord. 2007;21(1):105-17.

28 Hoyle RH, Stephenson MT, Palmgreen P, Lorch EP, Donohew RL. Reliability and validity of a brief measure of sensation seeking personality and individual differences. Addiction. 2002;32(3):401-14.

29 Boeldt DL, Schork NJ, Topol EJ, Bloss CS. Influence of individual differences in disease perception on consumer response to directto-consumer genomic testing. Clin Genet. 2015;87(3):225-32.

30 Fontenot K, Semega J, Kollar M; U.S. Census Bureau. Income and poverty in the United States: 2017. Washington, DC; 2018. Available from: https://www.census.gov/library/ publications/2018/demo/p60-263.html. 
31 Schwartz SW. Adolescent mental health in the United States. 2009. Available from: http://www.nccp.org/publications/pdf/ text_878.pdf.

32 Byck GR, Swann G, Schalet B, Bolland J, Mustanski $B$. Sensation seeking predicting growth in adolescent problem behaviors. Child Psychiatry Hum Dev. 2015;46(3):466-73.

33 Sabatello M. Psychiatric genomics and public mental health in the young mind. Am J Bioeth. 2017;17(4):27-9.

34 Condit CM. Laypeople are strategic essentialists, not genetic essentialists. Hastings Cent Rep. 2019;49(Suppl 1):S27-S37.

35 Hippman C, Lohn Z, Ringrose A, Inglis A, Cheek J, Austin JC. "Nothing is absolute in life": understanding uncertainty in the context of psychiatric genetic counseling from the perspective of those with serious mental illness. J Genet Couns. 2013;22(5):625-32.

36 Grealish A, Tai S, Hunter A, Emsley R, Murrells T, Morrison AP. Does empowerment mediate the effects of psychological factors on mental health, well-being, and recovery in young people? Psychol Psychother. 2017; 90(3):314-35.

37 Simonsen N, Lahti A, Suominen S, Välimaa R, Tynjälä J, Roos E, et al. Empowerment-enabling home and school environments and self-rated health among finnish adolescents. Health Promot Int. 2020 Feb 1;35(1):82-94.

38 Grealish A, Tai S, Hunter A, Morrison AP. Qualitative exploration of empowerment from the perspective of young people with psychosis. Clin Psychol Psychother. 2013; 20(2):136-48.

39 Semaka A, Austin J. Patient perspectives on the process and outcomes of psychiatric genetic counseling: an "empowering encounter”. J Genet Couns. 2019;28(4):856-68.

40 Jenkins S, Arribas-Ayllon M. Genetic counselling for psychiatric disorders: accounts of psychiatric health professionals in the United Kingdom. J Genet Couns. 2016;25:1243-55.

41 Finn CT, Smoller JW. Genetic counseling in psychiatry. Harv Rev Psychiatry. 2006;14(2): 109-21.

42 Peay H, McInerney J. A pilot study on psychiatric genetic counseling: counselors' needs. J Genet Couns. 2002;11:485.

43 Feret H, Conway L, Austin JC. Genetic counselors' attitudes towards individuals with schizophrenia: desire for social distance and endorsement of stereotypes. Patient Educ Couns. 2011;82(1):69-73.
44 Moldovan R, McGhee KA, Coviello D, Hamang A, Inglis A, Ingvoldstad Malmgren C, et al. Psychiatric genetic counseling: a mapping exercise. Am J Med Genet B Neuropsychiatr Genet. 2019;180(8):523-32.

45 Sabatello M, Appelbaum PS. Raising genomic citizens: adolescents and the return of secondary genomic findings. J Law Med Ethics. 2016; 44(2):292-308.

46 Duncan RE, Young MA. Tricky teens: are they really tricky or do genetic health professionals simply require more training in adolescent health? Per Med. 2013;10(6):589600.

47 Wildin B, Johansen-Taber K, Blazer K, Evans J, Ferber M, Johnson S, et al. Healthcare provider working group. 2017. https://www.genome.gov/Pages/About/OD/ECIB/GLEE/ GLEE_white_paper_ProviderEducation.pdf.

48 Palk AC, Dalvie S, de Vries J, Martin AR, Stein DJ. Potential use of clinical polygenic risk scores in psychiatry: ethical implications and communicating high polygenic risk. Philos Ethics Humanit Med. 2019;14(1):4.

49 Ryan J, Virani A, Austin JC. Ethical issues associated with genetic counseling in the context of adolescent psychiatry. Appl Transl Genom. 2015;5:23-9.

50 Úcar Martínez X, Jiménez-Morales M, Soler Masó P, Trilla Bernet J. Exploring the conceptualization and research of empowerment in the field of youth. Int J Adolesc Youth. 2017; 22(4):405-18

51 Cattaneo LB, Chapman AR. The process of empowerment: a model for use in research and practice. Am Psychol. 2010;65(7):64659.

52 Johnson C, Eva AL, Johnson L, Walker B. Don't turn away: empowering teachers to support students' mental health. Clearing House. 2011;84(1):9-14.

53 Dougherty MJ. Closing the gap: inverting the genetics curriculum to ensure an informed public. Am J Hum Genet. 2009;85(1):6-12.

54 Christens BD. Toward relational empowerment. Am J Community Psychol. 2012;50(12):114-28.

55 The Stanford Center on Poverty and Inequality (ed.). State of the Union 2017. Pathways Magazine. Available from: https://inequality. stanford.edu/sites/default/files/Pathways_ SOTU_2017.pdf.

$56 \mathrm{Yu} \mathrm{JH}$, Crouch J, Jamal SM, Tabor HK, Bamshad MJ. Attitudes of African Americans toward return of results from exome and whole genome sequencing. Am J Med Genet A. 2013; 161a(5):1064-72.
57 Lakes KD, Vaughan E, Lemke A, Jones M, Wigal T, Baker D, et al. Maternal perspectives on the return of genetic results: context matters. Am J Med Genet A. 2013;161a(1):38-47.

58 Michie M, Henderson G, Garrett J, CorbieSmith G. If I could in a small way help: motivations for and beliefs about sample donation for genetic research. J Empir Res Hum Res Ethics. 2011;6:57-70.

59 Sabatello M, Zhang Y, Chen Y, Appelbaum PS. In different voices: the views of people with disabilities about return of results from precision medicine research. Public Health Genomics. 2020;23(1-2):42-53.

60 Sabatello M, Chen Y, Zhang Y, Appelbaum PS. Disability inclusion in precision medicine research: a first national survey. Genet Med. 2019;21(10):2319-27.

61 National Academies of Sciences Engineering and Medicine (NASEM). Understanding disparities in access to genomic medicine: proceedings of a workshop. Washington, DC: The National Academies Press; 2018.

62 Claw KG, Anderson MZ, Begay RL, Tsosie KS, Fox K, Garrison NA. A framework for enhancing ethical genomic research with indigenous communities. Nat Commun. 2018;9(1):2957.

63 Kenen RH, Shapiro PJ, Hantsoo L, Friedman S, Coyne JC. Women with BRCA1 or BRCA2 mutations renegotiating a post-prophylactic mastectomy identity: self-image and self-disclosure. J Genet Couns. 2007;16(6):789-98.

64 Semaka A, Balneaves LG, Hayden MR. "Grasping the grey": patient understanding and interpretation of an intermediate allele predictive test result for Huntington disease. J Genet Couns. 2013;22:200-1.

65 Duncan RE, Gillam L, Savulescu J, Williamson R, Rogers JG, Delatycki MB. "Holding your breath": interviews with young people who have undergone predictive genetic testing for Huntington disease. Am J Med Genet A. 2007;143a:1984-9.

66 Blankenstein NE, Crone EA, van den Bos W, van Duijvenvoorde AC. Dealing with uncertainty: testing risk- and ambiguity-attitude across adolescence. Dev Neuropsychol. 2016; 41(1-2):77-92.

67 Horne J, Madill J, O’Connor C, Shelley J, Gilliland J. A systematic review of genetic testing and lifestyle behaviour change: are we using high-quality genetic interventions and considering behaviour change theory? Lifestyle Genom. 2018;11(1):49-63. 